\title{
pH, Viscosity of Hydrophobic Based Natural Deep Eutectic Solvents and the Effect of Curcumin Solubility in it
}

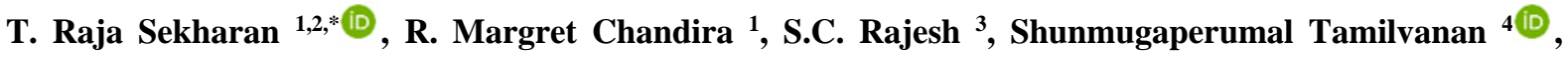 CT. Vijayakumar ${ }^{5}$, B.S. Venkateswarlu ${ }^{1}$}

1 Department of Pharmaceutics, Vinayaka Mission's College of Pharmacy, Vinayaka Mission's Research Foundation (Deemed to be University), Salem-636308, Tamil Nadu, India

2 Department of Pharmaceutics, Sankaralingam Bhuvaneswari College of Pharmacy, Anaikuttam-626130, Sivakasi, Tamil Nadu, India

3 Department of Pharmaceutical Analysis, Sankaralingam Bhuvaneswari College of Pharmacy, Anaikuttam-626130, Sivakasi, Tamil Nadu, India

4 Department of Pharmaceutics, National Institute of Pharmaceutical Education and Research (NIPER)-Guwahati, C/O NETES Institute of Technology \& Science, Mirza, Assam, India

5 Department of Polymer Technology, Kamaraj College of Engineering and Technology, K. Vellakulam, Madurai - 625 701, Tamilnadu, India

* Correspondence: rajasekharant2k@gmail.com;

Scopus Author ID 36114872000

Received: 5.02.2021; Revised: 5.03.2021; Accepted: 7.03.2021; Published: 25.03.2021

Abstract: Turmeric contains curcumin as one of the active constituents, which gives yellow color and possesses lots of pharmacological actions. Even though curcumin has lots of pharmacological actions till now, it has not been approved as a medicine due to its low water solubility, permeability, and poor bioavailability. Deep eutectic solvent (DES) can be prepared by simply mixing two or more solid components, [among the two one is hydrogen bond donor (HBD) and another is hydrogen bond acceptor (HBA)] at a definite molar ratio where the solid components by self-association converted into a liquid at room temperature (RT). Natural deep eutectic solvents (NADES) are a specific subgroup of DES containing primary plant-based metabolites such as organic acids, alcohols, amino acids, or sugars. In this work, natural hydrophobic DESs were prepared with Camphor, Menthol, and Thymol. This was prepared from different ratios of Menthol:Thymol 1:1 to 1:5 and 1:1 to 5:1 (MT-DES); Camphor:Thymol 1:1 to 1:5 and 1:1 to 5:1 (CT-NADES); Camphor:Menthol 1:1 to 1:5 and 1:1 to 2:1 (CM-NADES). The $\mathrm{pH}$ and viscosity of prepared DESs were determined with the help of a digital $\mathrm{pH}$ meter and Brookfield viscometer. The solubility of curcumin in different NADESs was determined at room temperature (RT) to higher temperatures. The formation of different clear DES was obtained with slight heat. There was no difference in $\mathrm{pH}$ for the NADESs prepared without and with heat. Regarding the viscosity CM-DES (1:1) showed less viscosity when compared to other NADESs. The solubility of curcumin was found to be nearly double when it was dissolved in NADES for $1 \mathrm{hr}$ at $35-40^{\circ} \mathrm{C}$ compared to $48 \mathrm{~h}$ stirring at 500 rotations per minute (rpm) at RT. Among different NADESs, curcumin solubility was found to be more in CM (1:1) ratio when compared to other NADESs.

Keywords: camphor; curcumin solubility; hydrophobic natural deep eutectic solvent; menthol; $\mathrm{pH}$; thymol; viscosity.

(C) 2021 by the authors. This article is an open-access article distributed under the terms and conditions of the Creative Commons Attribution (CC BY) license (https://creativecommons.org/licenses/by/4.0/). 


\section{Introduction}

Characteristic plant items have been utilized all through mankind's history for different pharmacological purposes. Between the years 1981 to 2002, nearly 877 drugs were launched globally, among them almost $61 \%$ from natural, manufactured goods [1]. The natural products give an auxiliary steer to unlock different secrecy behind mankind's healthiness, prevention, and healing of many diseases [2].

Turmeric (Curcuma longa) is a tuberous rhizomes (root-like structures) plant native to India and Indonesia [3]. Turmeric, mostly in powder form, is used as a cooking spice, and it is the only spice that is being in use for several devotional significance [4]. Turmeric is initially used as an additive in food processing, mainly as a flavoring and colorant in many countries. Turmeric is commonly and broadly in use most accepted traditional medicinal plants [5]. Turmeric has received much interest from both the medical/scientific worlds [6]. It is still being used as a medicine in various fields like Ayurvedha, Unani, and Siddha for treating various diseases [5].

Curcumin, one of the phytoconstituents, which provides the yellow color to turmeric, is widely used in ancient traditional herbal medicines to cure several diseases related to infection and inflammation for several decades [7]. Depending on the source, variation in soil condition, water condition, nutrition conditions, seasonal conditions, geographical variations, etc., the curcumin content in turmeric varies [8]. Curcuminoids content in turmeric varies from 2-9\% (w/w). Curcumin is the most abundant curcuminoid in turmeric [9].

In recent decades, curcumin has got increased consideration for its incredibly multiple pharmacological activities such as anti-inflammatory, antimicrobial, wound healing, antioxidant, anti-cancer, anti-fungal, and also antiviral [10] antineoplastic, antidiabetic, neuroprotective, cardiovascular protective properties, [11] antiproliferative, hypocholesterolemic, anti-thrombotic, antihepatotoxic, anti-diarrheal, carminative, diuretic, antirheumatic, hypotensive, larvicidal, insecticidal, anti-venomous, antityrosinase effects, etc. [12]. Even though curcumin contains extensive clinical use due to very low water solubility, permeability, and poor bioavailability, quick metabolism and systemic elimination hinder curcumin's direct use as biomedicine [13]. But curcumin is approved for nutritional purposes; curcumin is normally applied at a dose of $5-500 \mathrm{mg} / \mathrm{kg}$, depending on the food category [14]. US Food and Drug Administration certified turmeric as a "Generally Recognized as Safe" for pure curcumin; the acceptable daily intake limit is $2.5 \mathrm{mg} / \mathrm{kg}$ of body weight [15].

Deep eutectic solvents (DESs) were first reported by Abbott et al., DESs were prepared by simply mixing two or more solid components (at least one is HBD and another is HBA) at definite molar ratios the solid components by self-association converted into the liquid at RT. The melting point of the DES is far below that of the individual components [16].

DESs confirm attractive physical and chemical characteristics like low vapor pressure, non-inflammability, chemically tailorable, solvency power for a broad range of solutes, and water non-reactivity. Additionally, they can be effortlessly prepared from low toxicity, readily available, and inexpensive ingredients. Due to the -said properties, DESs have attracted increasing consideration as green solvents in different science areas [17]. DESs are used as an alternative to bulk organic solvents in numerous uses, particularly in extraction and electrochemistry by the various scientific community [18].

DESs composed of natural ingredients, mainly primary metabolites, are called Natural Deep Eutectic Solvents (NADESs). DESs are being reported as vehicles for dissolving various 
active pharmaceutical ingredients (APIs) and confirmed to show higher solubility in DESs than in water and increase the compound's stability [19]. Tamilvanan et al. suggest that the eutectic solvent may be of use to dissolve plant-derived active constituents [20].

Wikene et al. [21] evaluated the potential of curcumin dissolved in Natural Deep Eutectic Solvents (NADES) for the hydrophobic photosensitizer in antimicrobial photodynamic therapy. They prepared DES with the help of choline chloride, citric acid, fructose, glucose, glycerol, maleic acid, malic acid, sucrose, and trehalose from different ratios. They concluded that Maleic acid:Choline chloride (MC3) was a more efficient solvent when compared to other DESs. Curcumin $(1.25 \mu \mathrm{M})$ dissolved in MC3 was highly phototoxic towards E. coli. However, MC3 leads to a photolabile product, and light protection should be considered. So they suggested storing the products without dilution to avoid precipitation and hydrolysis of curcumin.

Rachmaniah et al. [22] extracted curcuminoids from Curcuma zeodaria with the help of acidic type NADES malic acid:sucrose:water (MA:S: $\mathrm{H}_{2} \mathrm{O}=1: 1: 11$, mole ratio) and citric acid:sucrose:water (CA:S: $\mathrm{H}_{2} \mathrm{O}=1: 2: 15$, mole ratio). The viscosity was high, so they added up to $60 \%$ of water content to reduce the viscosity of the NADES. They successfully extracted curcuminoids from both the type of NADES. They concluded that curcuminoids are more stable in CA:S: $\mathrm{H}_{2} \mathrm{O}$ compare to $\mathrm{MA}: \mathrm{S}: \mathrm{H}_{2} \mathrm{O}$ for $96 \mathrm{~h}$ of time duration.

Jeliński et al. [23] determined the solubility and stability of curcumin in NADES. The NADES is made up of choline chloride as a hydrogen bond acceptor combined with glycerol, fructose, glucose, sorbitol, xylitol, sucrose, and maltose as a hydrogen bond donor in different ratios. Their results concluded that NADES comprising the unimolar proportion of choline chloride and glycerol gave the highest curcumin solubility.

Almeida et al. [24] aimed to discover the effects of curcumin dye in DES, based on choline chloride and lactic acid (1:1) on the mechanical, optical, and barrier properties of chitosan films. They concluded that the attained films had been revealed to be very promising as a precursor for the manufacture of chitosan films for food packaging.

The chemical structure of curcumin is shown in figure 1, and the structure of Thymol, Menthol, and Camphor are shown in figure 2

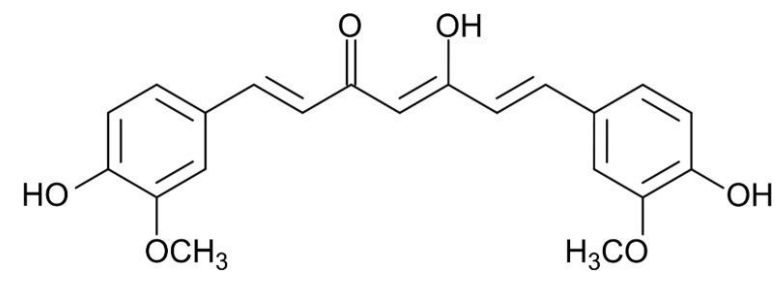

Figure 1. Structure of Curcumin.

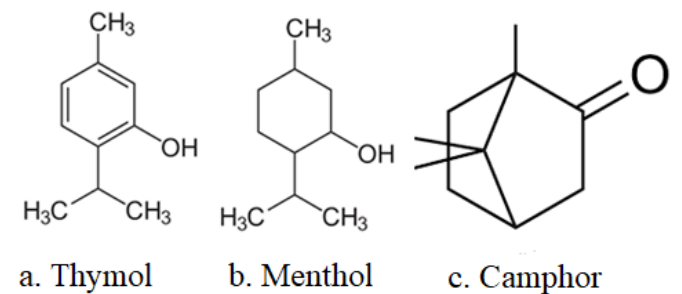

Figure 2. Structure of a. Thymol, b. Menthol, and c. Camphor.

The present study aimed to prepare different hydrophobic-based NADESs containing natural substances like camphor, menthol, and thymol without and with heat. The $\mathrm{pH}$ and viscosity of the prepared hydrophobic NADESs were determined with the help of the pH meter 
and Brookfield viscometer. Several researchers have studied the solubility of curcumin in different organic solvents, oils, etc.; however, a detailed study of curcumin in hydrophobic based NADES (camphor, menthol, and thymol) at various ratios (1:1 to 1:5), at different temperatures (RT to $80^{\circ} \mathrm{C}$ ) is not reported. Keeping in this in the mind in the present study, the effect of temperature on curcumin's solubility is investigated in detail with UV double beam spectrophotometer.

\section{Materials and Methods}

Curcumin was procured from Sami labs limited, Camphor and Thymol were purchased from Sisco research laboratories Pvt; Ltd, Maharastra, Menthol was procured from Reachem Laboratory chemicals Pvt; Ltd, Chennai. Methanol was bought from Himedia Laboratory Pvt; Ltd. Mumbai. Distilled water was secured from Rajco Pvt; Ltd, Sivakasi. All other chemicals utilized in this study for preparing different buffers were of analytical grade.

\subsection{Preparation of hydrophobic NADESs.}

NADES was prepared with slight modification previously performed by Phaechamud et al. [25] NADES was prepared by mixing various proportions of eutectic forming ingredients (camphor, menthol, and thymol) with the assistance of a magnetic stirrer. An accurately weighed amount of eutectic forming ingredients were taken in a screw-capped glass bottle, a magnetic bead was placed inside the glass bottle, and the glass bottle was closed tightly with the cap. The screw-capped bottle was kept in a magnetic stirrer and rotated at $500 \mathrm{rpm}$ at RT for $48 \mathrm{hrs}$. If necessary slight heat $\left(35-40^{\circ} \mathrm{C}\right)$ or more heat was applied to prepare DESs.

\section{2. $p H$ determination for the hydrophobic NADESs.}

A $\mathrm{pH}$ meter instrument is used to determine the acidity or alkalinity of a solution referred to as $\mathrm{pH}$ or hydrogen ion concentration. The term $\mathrm{pH}$ is derived from " $\mathrm{p}$," the mathematical symbol for negative logarithm, and " $\mathrm{H}$," the chemical symbol for hydrogen. $\mathrm{pH}$ is measured on a scale of 0 to 14 [26].

The $\mathrm{pH}$ of NADES formulation was determined using a Digital $\mathrm{pH}$ meter (Eutech Instruments, Malaysia). The glass electrode was calibrated with the $\mathrm{pH} 4.0$ buffer solutions determined for the equipment. The $\mathrm{pH}$ was determined by dipping the electrode (previously rinsed in deionized water and wipe it with tissue paper) in the NADES system, waited for some time until the reading becomes steady, and then the readings were noted. The analysis of $\mathrm{pH}$ of NADES was done in triplicate, and average values were calculated.

\subsection{Viscosity determination.}

The viscosity of the prepared NADESs was determined with the help of Brookfield digital viscometer (DV-E model). Based on the spindle's speed and characteristics, a direct reading of the viscosity in $\mathrm{mPa} \cdot \mathrm{s}$ was noted. For this study, the viscosity of the NADES was recorded using spindle number 18. The spindle was submerged into the NADES; the viscometer measures the resistance (flow viscosity) of the NADES at $60 \mathrm{rpm}$ [27]. 


\subsection{Curcumin solubility determinations in different hydrophobic NADESs.}

Solubility is defined as the amount of substance that passes into a solution to achieve a saturated solution at constant temperature and pressure. Curcumin solubility in different NADES at RT was prepared with slight modification previously performed by Phaechamud et al. [24]. The equilibrium curcumin solubility in several NADES was determined with the assistance of a magnetic stirrer. A small amount of curcumin was added into $10 \mathrm{ml}$ of hydrophobic TM-DES (1:1 to 1:5) and mixed well with the help of a magnetic stirrer at 500 $\mathrm{rpm}$ for $48 \mathrm{~h}$ at RT. If the initially added curcumin was dissolved completely, then an additional quantity of curcumin was added to the natural hydrophobic TM-DES until some curcumin remains undissolved to form a saturated solution in equilibrium with the solid phase.

Curcumin solubility in different NADES with slight heat was prepared with slight modification previously performed by Duarte et al. [28]. By this method, excess curcumin was added to the hydrophobic NADES prepared with TM (1:1 to 1:5) and allowed to mix in a magnetic stirrer for $1 \mathrm{hr}$ at $500 \mathrm{rpm}$ at $35-40^{\circ} \mathrm{C}$. The saturation was confirmed by observation of the presence of un-dissolved curcumin. Then the saturated solution was kept overnight in a closed container for the settlement of undissolved curcumin. On a subsequent day, the saturated solution was centrifuged at $10,000 \mathrm{rpm}$ for $20 \mathrm{~min}$, and the temperature was maintained at $27^{\circ} \mathrm{C}$ to obtain a clear yellow color supernatant solvent.

About $1 \mathrm{ml}$ of the supernatant clear NADES was made up to $10 \mathrm{ml}$ with methanol, and $1 \mathrm{ml}$ of the above was taken and makeup to $10 \mathrm{ml}$ with buffer $\mathrm{pH} 5.5$ of $50 \mathrm{mM}$ sodium dihydrogen orthophosphate contains 5\% SLS. UV spectroscopy is the most common and easiest analytical method to determine solubility. The samples were analyzed in a UV double beam spectrophotometer at $430 \mathrm{~nm}$. Curcumin solubility in other natural hydrophobic NADES (MT, CT, and CM) was decided based on the results obtained from TM with and without heat.

\section{Results and Discussion}

\subsection{Preparation of hydrophobic NADESs.}

The NADES was initially prepared with the help of a magnetic stirrer at RT. As the concentration of one ingredient was increased, there was difficult or no formation of DES at RT, so slight heat was applied for DES formation. Solid/solute substances are held together by intermolecular attraction. In general, increasing the temperature increases the solubility of many solids in liquids. When the liquid's temperature increases, its kinetic energy also increases, which makes the liquid break the solids more effectively or dissolve more readily because the solids are less capable of holding together.

At first, NADES was prepared with thymol and menthol in a different molar ratio by mixing it with a magnetic stirrer's assistance at $500 \mathrm{rpm}$ at RT. Formation of DES occurs within 10 to $20 \mathrm{~min}$ for TM $(1: 1,1: 2$, and 2:1) at RT. For MT (1:3), it took $12 \mathrm{~h}$ for the formation of DES at RT. TM (1:3 to 1:5) and MT (1:4 and 1:5) showed hazy liquid even after it had been stirred for $48 \mathrm{hrs}$ at RT. After $24 \mathrm{hrs,} \mathrm{NADES} \mathrm{clarity} \mathrm{was} \mathrm{checked,} \mathrm{except} \mathrm{for} \mathrm{MT} \mathrm{(1:3)} \mathrm{no}$ progressions were found for the rest of the NADES. The result for the formation of MT-DESs or TM-DESs without heat is shown in Table 1.

Table 1. Preparation of TM-based hydrophobic NADES without heat.

\begin{tabular}{l|c|c|c|c} 
DES & Molar ratio & Conditions & Appearance & Appearance after 24 h \\
\hline MT & $1: 1$ & $10 \mathrm{~min} ; 500 \mathrm{rpm}$ & Clear liquid & Clear liquid \\
\hline MT & $1: 2$ & $20 \mathrm{~min} ; 500 \mathrm{rpm}$ & Clear liquid & Clear liquid \\
https://biointerfaceresearch.com/ & & & $\mathbf{1 4 6 2 4}$
\end{tabular}




\begin{tabular}{l|c|c|c|c}
\hline DES & Molar ratio & Conditions & Appearance & Appearance after 24 h \\
\hline MT & $1: 3$ & $12 \mathrm{hrs} ; 500 \mathrm{rpm}$ & Clear liquid & Slight hazy liquid \\
\hline MT & $1: 4$ & $48 \mathrm{hrs} ; 500 \mathrm{rpm}$ & Hazy liquid & Hazy liquid \\
\hline MT & $1: 5$ & $48 \mathrm{hrs} ; 500 \mathrm{rpm}$ & Hazy liquid & Hazy liquid \\
\hline TM & $1: 1$ & $10 \mathrm{~min} ; 500 \mathrm{rpm}$ & Clear liquid & Clear liquid \\
\hline TM & $1: 2$ & $20 \mathrm{~min} ; 500 \mathrm{rpm}$ & Clear liquid & Clear liquid \\
\hline TM & $1: 3$ & $48 \mathrm{hrs} ; 500 \mathrm{rpm}$ & Hazy liquid & Hazy liquid \\
\hline TM & $1: 4$ & $48 \mathrm{hrs} ; 500 \mathrm{rpm}$ & Hazy liquid & Hazy liquid \\
\hline TM & $1: 5$ & $48 \mathrm{hrs} ; 500 \mathrm{rpm}$ & Hazy liquid & Hazy liquid
\end{tabular}

From the above result for further studies, slight heat $\left(35-40^{\circ} \mathrm{C}\right)$ was applied to prepare clear NADES. At the point when slight heat $\left(35-40^{\circ} \mathrm{C}\right)$ was applied to TM-1:1, clear DES formed within 10 min for TM-1:2 and MT-2:1 clear DES formed within 15 min, for TM-1:3 and MT-3:1 clear DES formed within $30 \mathrm{~min}$ and 25 min respectively. For MT-1:4, clear DES formed within $45 \mathrm{~min}$, whereas for TM-1:4, TM-1:5, and MT-1:5, clear DES formed at $1 \mathrm{~h}$. The formed clear DES was kept in a closed container for $24 \mathrm{hrs,}$, and its clarity was checked after 24 hrs. All the DES prepared with different molar ratios were seen to be clear significantly after 24 hrs. The result for the formation of MT-DESs or TM-DESs with slight heat is shown in Table 2.

Table 2. Preparation of TM-based hydrophobic NADES with slight heat.

\begin{tabular}{c|c|c|c} 
DES Code & Conditions & Appearance & Appearance after 24 h \\
\hline MT-1:1 & $10 \mathrm{~min} ; 35-40^{\circ} \mathrm{C} ; 500 \mathrm{rpm}$ & Clear liquid & Clear liquid \\
\hline MT-1:2 & $15 \mathrm{~min} ; 35-40^{\circ} \mathrm{C} ; 500 \mathrm{rpm}$ & Clear liquid & Clear liquid \\
\hline MT-1:3 & $25 \mathrm{~min} ; 35-40^{\circ} \mathrm{C} ; 500 \mathrm{rpm}$ & Clear liquid & Clear liquid \\
\hline MT-1:4 & $45 \mathrm{~min} ; 35-40^{\circ} \mathrm{C} ; 500 \mathrm{rpm}$ & Clear liquid & Clear liquid \\
\hline MT-1:5 & $1 \mathrm{hrs} ; 35-40^{\circ} \mathrm{C} ; 500 \mathrm{rpm}$ & Clear liquid & Clear liquid \\
\hline TM-1:1 & $10 \mathrm{~min} ; 35-40^{\circ} \mathrm{C} ; 500 \mathrm{rpm}$ & Clear liquid & Clear liquid \\
\hline TM-1:2 & $15 \mathrm{~min} ; 35-40^{\circ} \mathrm{C} ; 500 \mathrm{rpm}$ & Clear liquid & Clear liquid \\
\hline TM-1:3 & $30 \mathrm{~min} ; 35-40^{\circ} \mathrm{C} ; 500 \mathrm{rpm}$ & Clear liquid & Clear liquid \\
\hline TM-1:4 & $1 \mathrm{hrs} ; 35-40^{\circ} \mathrm{C} ; 500 \mathrm{rpm}$ & Clear liquid & Clear liquid \\
\hline TM-1:5 & $1 \mathrm{hrs} ; 35-40^{\circ} \mathrm{C} ; 500 \mathrm{rpm}$ & Clear liquid & Clear liquid
\end{tabular}

The lone electron pairs of the oxygen in thymol are delocalized through the aromatic ring, making its hydroxyl group more positive than normal, and the chemical structure of thymol includes contributions from all of its resonance structures, resulting in oxygen with sp2 character. As a result, oxygen becomes a weak hydrogen bond acceptor, while the bound proton becomes a stronger hydrogen bond donor.

Thymol is an unadulterated fluid state hydrogen bond found to be between a good hydrogen bond donor and a poor hydrogen bond acceptor. The absence of aromaticity for menthol in the unadulterated fluid state possesses a normal hydroxyl group. When thymol and menthol are mixed together, an optimal relationship occurs in which the hydrogen bond of thymol (a superior to standard hydrogen bond donor) interacts well with the oxygen of menthol, resulting in a stronger hydrogen bond than in the pure fluid state. Both thymol and menthol exhibit a significant negative deviation from ideality as a result of this.

Since clear NADES was achieved by applying slight heat $\left(35-40^{\circ} \mathrm{C}\right)$ for the previous TM, the CT-DES with different molar ratios was also prepared with the help of slight heat (35$\left.40^{\circ} \mathrm{C}\right)$. At the point when slight heat $\left(35-40^{\circ} \mathrm{C}\right)$ was applied to TC-1:1, 1:2 and CT $-1: 1,1: 2$ clear DES formed within 10 min, for TC-1:3 and CT-3:1 clear DES formed within 20 min, for TC-1:4 and CT-4:1 clear DES formed within $40 \mathrm{~min}$. TC-1:5 and CT-5:1 clear DES formed within $1 \mathrm{hr}$. The formed clear DES was kept in a closed container for $24 \mathrm{hrs}$, and its clearness was checked after $24 \mathrm{hrs}$. All the CT-DES prepared with different molar ratios was seen as 
clear considerably even after $24 \mathrm{hrs}$. The result for the formation of CT-DESs or TC-DESs with slight heat is shown in Table 3 .

Table 3. Preparation of TC-based natural hydrophobic DES with heat.

\begin{tabular}{c|c|c|c} 
DES Code & Conditions & Appearance & Appearance after 24 hrs \\
\hline CT-1:1 & $10 \mathrm{~min} ; 35-40^{\circ} \mathrm{C} ; 500 \mathrm{rpm}$ & Clear liquid & Clear liquid \\
\hline $\mathrm{CT}-1: 2$ & $10 \mathrm{~min} ; 35-40^{\circ} \mathrm{C} ; 500 \mathrm{rpm}$ & Clear liquid & Clear liquid \\
\hline $\mathrm{CT}-1: 3$ & $20 \mathrm{~min} ; 35-40^{\circ} \mathrm{C} ; 500 \mathrm{rpm}$ & Clear liquid & Clear liquid \\
\hline $\mathrm{CT}-1: 4$ & $40 \mathrm{~min} ; 35-40^{\circ} \mathrm{C} ; 500 \mathrm{rpm}$ & Clear liquid & Clear liquid \\
\hline $\mathrm{CT}-1: 5$ & $1 \mathrm{hr} ; 35-40{ }^{\circ} \mathrm{C} ; 500 \mathrm{rpm}$ & Clear liquid & Clear liquid \\
\hline TC-1:1 & $10 \mathrm{~min} ; 35-40^{\circ} \mathrm{C} ; 500 \mathrm{rpm}$ & Clear liquid & Clear liquid \\
\hline TC-1:2 & $10 \mathrm{~min} ; 35-40^{\circ} \mathrm{C} ; 500 \mathrm{rpm}$ & Clear liquid & Clear liquid \\
\hline TC-1:3 & $20 \mathrm{~min} ; 35-40^{\circ} \mathrm{C} ; 500 \mathrm{rpm}$ & Clear liquid & Clear liquid \\
\hline TC-1:4 & $40 \mathrm{~min} ; 35-40^{\circ} \mathrm{C} ; 500 \mathrm{rpm}$ & Clear liquid & Clear liquid \\
\hline TC-1:5 & $1 \mathrm{hr} ; 35-40^{\circ} \mathrm{C} ; 500 \mathrm{rpm}$ & Clear liquid & Clear liquid
\end{tabular}

Preparation of clear NADES was achieved by applying slight heat $\left(35-40^{\circ} \mathrm{C}\right)$ in $\mathrm{CM}$ and $\mathrm{MC}$ with various molar ratios. When slight heat $\left(35-40^{\circ} \mathrm{C}\right)$ was applied to $\mathrm{CM}-1: 1$ and 1:2 clear DES formed within 10 min. For CM-1:3, 1:4, and 1:5 clear DES formed within 20 min, $40 \mathrm{~min}$, and $1 \mathrm{hr}$, respectively. TC-1:5 and 5:1 clear DES formed within $1 \mathrm{hr}$. The formed clear DES was kept in a closed container for $24 \mathrm{hrs,} \mathrm{and} \mathrm{its} \mathrm{clarity} \mathrm{was} \mathrm{checked} \mathrm{after} 24 \mathrm{hrs}$. All the DES prepared with various molar ratios were seen as clear significantly after $24 \mathrm{hrs}$.

When menthol was kept constant, and the camphor concentration was increased to twofold, the concentration even slight heat is applied for a while of $30 \mathrm{~min}$ the solvent isn't clear it was seen to be hazy. So it was decided to increase the temperature to $45-50^{\circ} \mathrm{C}$ and the stirring time was for $30 \mathrm{~min}$ still, the solvent was found to be hazy, then the stirring time was increased to $1 \mathrm{hr}$, and the temperature was kept between $45-50^{\circ} \mathrm{C}$. Still, the solvent was found to be hazy. So the temperature was further increased to $55-60^{\circ} \mathrm{C}$, and the stirring time was kept for $1 \mathrm{hr}$; still, the solvent was found to be hazy. The temperature was further increased to 65$70^{\circ} \mathrm{C}$, and the stirring time was kept for $1 \mathrm{hr}$; still, the solvent was found to be hazy. The temperature was further increased to $75-80^{\circ} \mathrm{C}$, and the stirring time was kept for $1 \mathrm{hr}$, now the solvent was found to be clear.

MC-1:3 when slightly heated between $35-40^{\circ} \mathrm{C}$ for a period of $1 \mathrm{hr}$ it showed gel-like consistency, there was no formation of clear solvent, so its temperature was increased to 75 $80^{\circ} \mathrm{C}$ and allowed to rotate for $1 \mathrm{hr}$, the clear liquid was formed after $1 \mathrm{hr}$ mixing. The formed clear NADES was kept in a closed container for $24 \mathrm{hrs}$, and its lucidity was checked after 24 hrs. At 24 hrs, the NADES was not found to be a clear solvent; it looks like a gel-like consistency.

MC-1:4 and 1:5 when slightly heated between $35-40^{\circ} \mathrm{C}$ for a period of $1 \mathrm{hr}$ it showed solid-like consistency, there was no formation of clear solvent, so its temperature was increased to $75-80^{\circ} \mathrm{C}$ and permitted to pivot for $1 \mathrm{hr}$, no formation of clear liquid after $1 \mathrm{hr}$ mixing. The formed gel-like consistency NADES was kept in a closed container for $24 \mathrm{hrs}$, and its consistency was checked after $24 \mathrm{hrs}$. At $24 \mathrm{hrs}$, the NADES was seen to be solid like consistency. The result for the formation of CM-DESs or MC-DESs with slight heat is shown in Table 4.

Table 4. Preparation of CM-based hydrophobic NADES with heat.

\begin{tabular}{c|c|c|c} 
DES Code & Conditions & Appearance & Appearance after 24 hrs \\
\hline $\mathrm{CM}-1: 1$ & $10 \mathrm{~min} ; 35-40^{\circ} \mathrm{C} ; 500 \mathrm{rpm}$ & Clear liquid & Clear liquid \\
\hline $\mathrm{CM}-1: 2$ & $10 \mathrm{~min} ; 35-40^{\circ} \mathrm{C} ; 500 \mathrm{rpm}$ & Clear liquid & Clear liquid \\
\hline $\mathrm{CM}-1: 3$ & $20 \mathrm{~min} ; 35-40^{\circ} \mathrm{C} ; 500 \mathrm{rpm}$ & Clear liquid & Clear liquid \\
\hline $\mathrm{CM}-1: 4$ & $40 \mathrm{~min} ; 35-40^{\circ} \mathrm{C} ; 500 \mathrm{rpm}$ & Clear liquid & Clear liquid
\end{tabular}




\begin{tabular}{c|c|c|c} 
DES Code & Conditions & Appearance & Appearance after 24 hrs \\
\hline $\mathrm{CM}-1: 5$ & $1 \mathrm{hr} ; 35-40^{\circ} \mathrm{C} ; 500 \mathrm{rpm}$ & Clear liquid & Clear liquid \\
\hline MC-1:1 & $10 \mathrm{~min} ; 35-40^{\circ} \mathrm{C} ; 500 \mathrm{rpm}$ & Clear liquid & Clear liquid \\
\hline MC-1:2 & $30 \mathrm{~min} ; 35-40^{\circ} \mathrm{C} ; 500 \mathrm{rpm}$ & Hazy liquid & Hazy liquid \\
\hline MC-1:2 & $30 \mathrm{~min} ; 45-50^{\circ} \mathrm{C} ; 500 \mathrm{rpm}$ & Hazy liquid & Hazy liquid \\
\hline MC-1:2 & $1 \mathrm{hr} ; 45-50^{\circ} \mathrm{C} ; 500 \mathrm{rpm}$ & Hazy liquid & Hazy liquid \\
\hline MC-1:2 & $1 \mathrm{hr} ; 55-60^{\circ} \mathrm{C} ; 500 \mathrm{rpm}$ & Hazy liquid & Hazy liquid \\
\hline MC-1:2 & $1 \mathrm{hr} ; 65-70^{\circ} \mathrm{C} ; 500 \mathrm{rpm}$ & Hazy liquid & Hazy liquid \\
\hline MC-1:2 & $1 \mathrm{hr} ; 75-80^{\circ} \mathrm{C} ; 500 \mathrm{rpm}$ & Clear liquid & Clear liquid \\
\hline $\mathrm{MC}-1: 3$ & $1 \mathrm{hr} ; 35-40^{\circ} \mathrm{C} ; 500 \mathrm{rpm}$ & Gel like & Gel like \\
\hline MC-1:3 & $1 \mathrm{hr} ; 75-80^{\circ} \mathrm{C} ; 500 \mathrm{rpm}$ & Clear liquid & Gel like \\
\hline $\mathrm{MC}-1: 4$ & $1 \mathrm{hr} ; 35-40^{\circ} \mathrm{C} ; 500 \mathrm{rpm}$ & Solid & Solid \\
\hline $\mathrm{MC}-1: 4$ & $1 \mathrm{hr} ; 75-80^{\circ} \mathrm{C} ; 500 \mathrm{rpm}$ & Gel like & Solid \\
\hline $\mathrm{MC}-1: 5$ & $1 \mathrm{hr} ; 35-40^{\circ} \mathrm{C} ; 500 \mathrm{rpm}$ & Solid & Solid
\end{tabular}

Camphor is an alicyclic ketone and is present in a bicyclic ring system. Owing to the electron negative oxygen in the keto group, the $\pi$ electrons are closer to oxygen, and hence carbon gets a partial positive charge, and the oxygen gets a partial negative charge. If we consider the structure of menthol, it is alicyclic secondary alcohol. Thymol is an alkyl substituted phenol; it is well known that phenols are acidic while alcohols are neutral. Hence phenol forms stronger hydrogen bonds than aliphatic or alicyclic alcohols, so phenol is more soluble in dipolar solvents like water than alcohol.

Based on camphor, menthol, and thymol's structure, it is reasonable to expect stronger interactions in the case of the camphor-menthol system. The hindrance of interaction between camphor and thymol may be safely attributed to the acidic nature of thymol. Our experimental results indicate CM-DESs form comparatively easily.

\section{2. $\mathrm{pH}$ determination for the hydrophobic NADESs.}

The $\mathrm{pH}$ value of a substance is directly connected to the proportion of the hydrogen ion $\left[\mathrm{H}^{+}\right]$and the hydroxyl ion $\left[\mathrm{OH}^{-}\right]$concentrations. If the $\mathrm{H}^{+}$concentration is larger than $\mathrm{OH}^{-}$, the substance is acidic; i.e., the $\mathrm{pH}$ measurement is less than 7. If the $\mathrm{OH}^{-}$concentration is larger than $\mathrm{H}^{+}$, the substance is basic, with a $\mathrm{pH}$ value greater than 7. If equal amounts of $\mathrm{H}^{+}$and $\mathrm{OH}^{-}$ ions are present, the substance is neutral, with a $\mathrm{pH}$ of 7 . The $\mathrm{pH}$ of all the NADESs was determined with the help of a $\mathrm{pH}$ meter. TM-DES at different ratios $\mathrm{pH}$ was determined by simply dipping the electrode in the NADES, and the readings were noted. The $\mathrm{pH}$ data of TMbased DES prepared with and without heat was shown in figure 3, and the $\mathrm{pH}$ of other DES prepared with slight heat was shown in figure 4.

The $\mathrm{pH}$ of the DESs prepared at RT for TM-1:1 to 1:5 at different molar ratios was between $6.667 \pm 0.037$ to $6.990 \pm 0.037$. The $\mathrm{pH}$ of the DESs prepared with slight heat $\left(35-40^{\circ} \mathrm{C}\right)$ for TM-1:1 to $1: 5$ at different molar ratios was found to be between $6.667 \pm 0.051$ to $6.983 \pm 0.040$. The $\mathrm{pH}$ of the DESs prepared at RT for MT-1:1 to 1:5 at different molar ratio was found to be between $6.667 \pm 0.037$ to $6.557 \pm 0.037$. The $\mathrm{pH}$ of the DESs prepared with slight heat $\left(35-40^{\circ} \mathrm{C}\right)$ for MT-1:1 to 1:5 at different molar ratio was found to be between $6.677 \pm 0.051$ to $6.540 \pm 0.044$.

It was observed that when the concentration of thymol was kept constant and increased in menthol concentration has increased the $\mathrm{pH}$ of the DES. The data showed no significant difference in $\mathrm{pH}$ when the DESs were prepared with RT and slight heat $\left(35-40^{\circ} \mathrm{C}\right)$.

The $\mathrm{pH}$ of the DESs prepared with slight heat $\left(35-40^{\circ} \mathrm{C}\right)$ for TC-1:1 to $1: 5$ at different molar ratios was found to be between $5.943 \pm 0.035$ to $6.393 \pm 0.047$. The results showed that 
when the concentration of thymol was kept constant and an increase in camphor concentration has increased the $\mathrm{pH}$ of the DES.

The $\mathrm{pH}$ of the DESs prepared with slight heat $\left(35-40^{\circ} \mathrm{C}\right)$ for CT-1:1 to $1: 5$ at different molar ratios was found to be between $5.943 \pm 0.035$ to $5.893 \pm 0.065$. The results showed that when the concentration of camphor was kept constant and the thymol concentration was increased initially, there was a decrease in the $\mathrm{pH}$ followed by an increase in the $\mathrm{pH}$.

The $\mathrm{pH}$ of the DESs prepared with slight heat $\left(35-40^{\circ} \mathrm{C}\right)$ for $\mathrm{CM}-1: 1$ to $1: 5$ at different molar ratios was found to be between $5.607 \pm 0.061$ to $5.637 \pm 0.067$. The results showed that when the camphor concentration was kept constant and the increase in menthol concentration, there was an increase in $\mathrm{pH}$ followed by a decrease in the $\mathrm{pH}$.

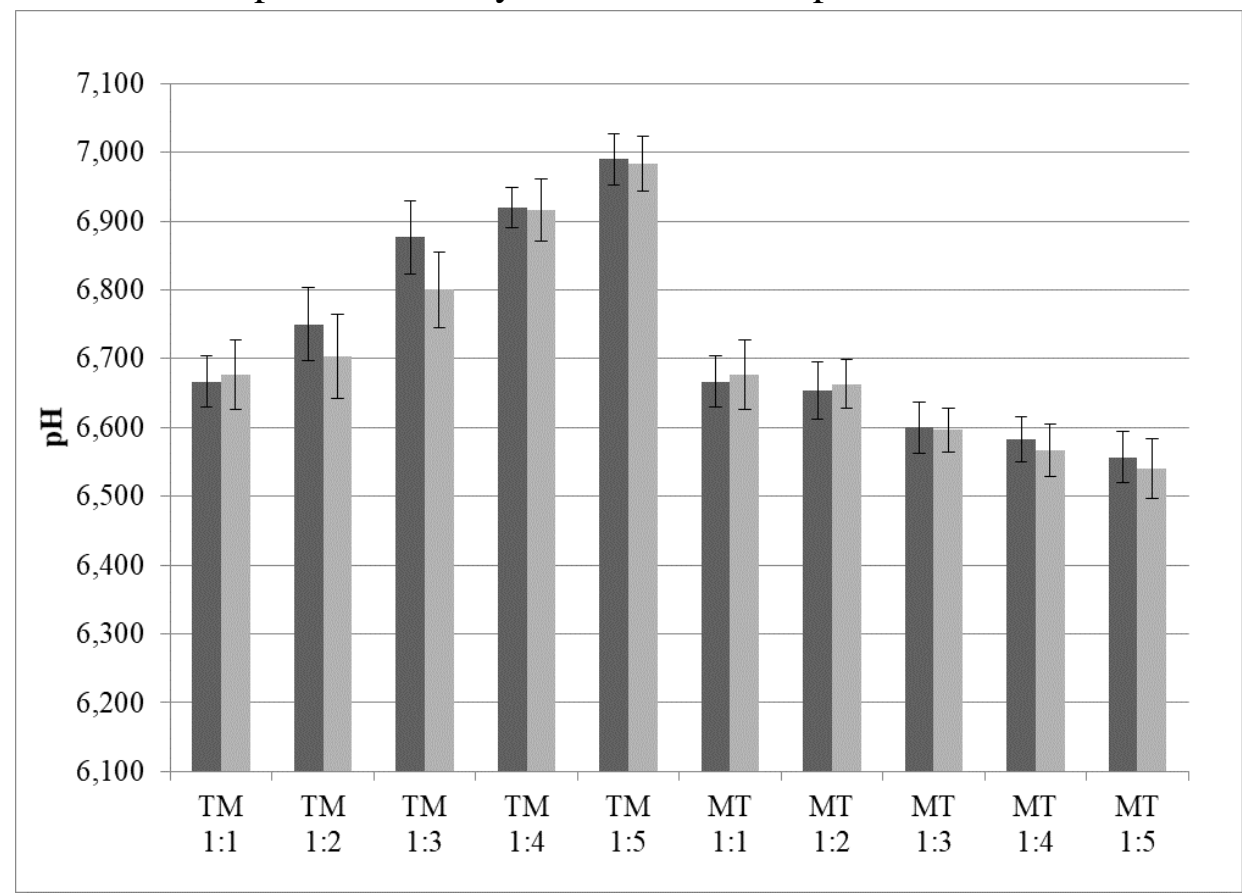

Figure 3. The pH of TM base hydrophobic NADES prepared with and without heat.

$(\square)$ without heat $(\square)$ with heat

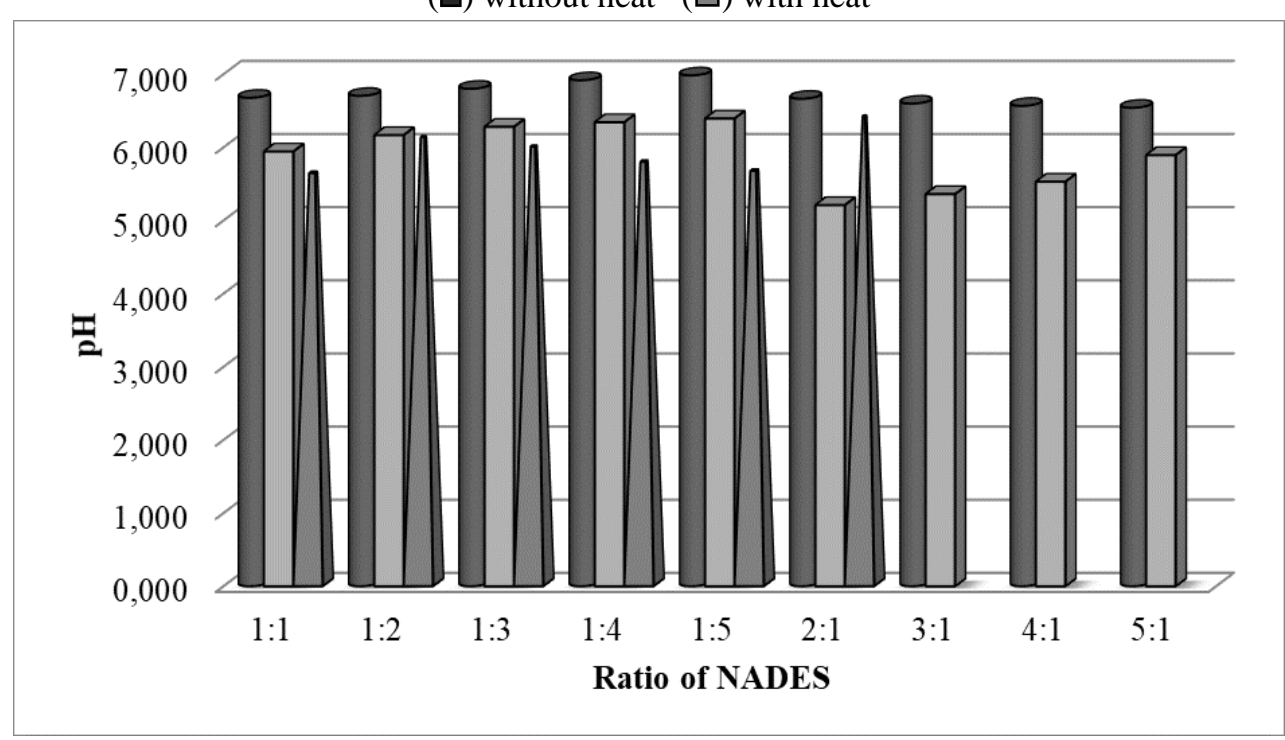

Figure 4. The $\mathrm{pH}$ of different hydrophobic NADES prepared with slight heat.

( $\mathrm{\theta})-\mathrm{TM},(\triangle)-\mathrm{TC}$, ( $\square)-\mathrm{MC}$

The $\mathrm{pH}$ of the DES prepared with slight heat $\left(35-40^{\circ} \mathrm{C}\right)$ for $\mathrm{MC}-1: 1$ and 1:2 was found to be between $5.693 \pm 0.095$ and $6.380 \pm 0.066$. The $\mathrm{pH}$ was not checked for the remaining ratio of MC-1:3 to 1:5 due to gel-like consistency and solid-like form. The results showed that when 
the concentration of menthol was kept constant and an increase in camphor concentration has increased the $\mathrm{pH}$ of the DES.

\subsection{Viscosity of different hydrophobic NADESs.}

Since DESs are mainly used as solvents, their typical high viscosity is a major drawback. For the effortlessness of formulation development, the viscosity should be as low as possible. According to the industry aspects, the high viscosity of liquid will lead to larger energy costs and can cause problems in any/all pharmaceutical processing like handling, transferring, mixing, and filling. Osch et al. [29] suggested that viscosities up to $100 \mathrm{mPa}$.s are still acceptable for industrial applications. Dwamena [30] suggests the strength of the hydrogen bond determines the viscosity of the DES. According to Emami and Shayanfar [17] the viscosity of most of the DESs are 100-1000 times more viscous when compared to water and common organic solvents. According to Skulcova [31], extensive hydrogen bonding arrangement and Van der Waals interactions between each component result in high viscosity of DESs.

Understanding the charge transfer and the molecular interaction between HBD and HBA occurring in hydrophobic DES is a precious opportunity for upcoming research. The results suggested that DES prepared with CM-1:1 showed less viscosity when compared to other DESs prepared with CT and TM. The viscosity of the different natural hydrophobic DESs was measured after preparation, which is presented in figure 5.

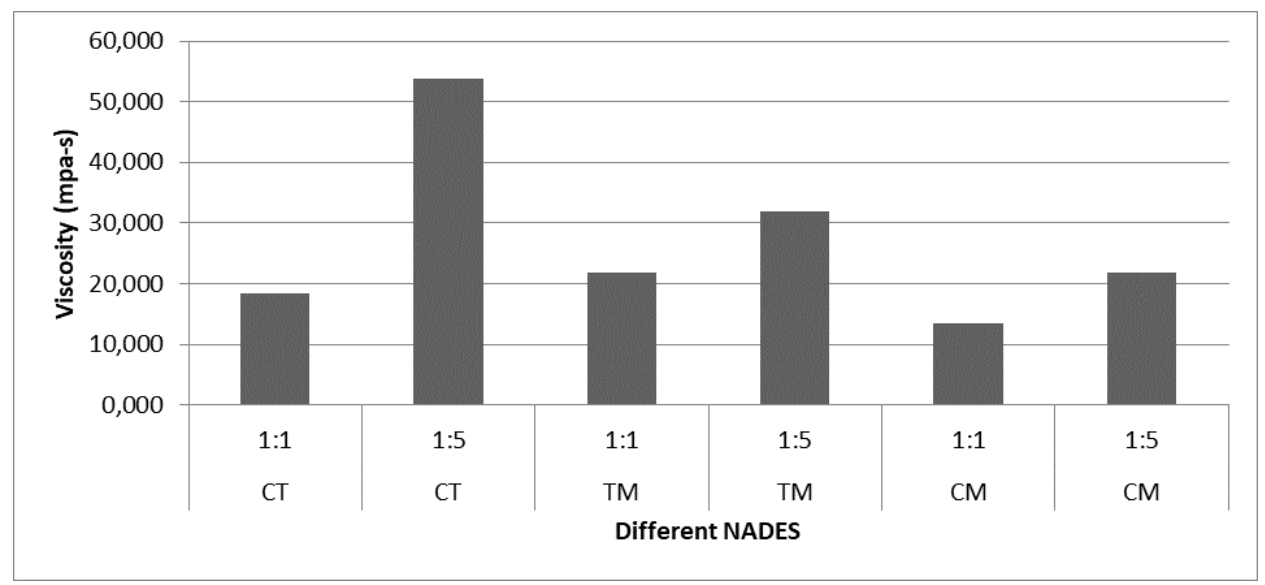

Figure 5. The viscosity of different hydrophobic based NADES.

\subsection{Curcumin solubility in different hydrophobic NADESs.}

Poor aqueous solubility is likely to increase formulation difficulties during clinical development. Thus it is of interest to accurately measure the solubility of sparingly soluble compounds. It is well known that due to its hydrophobic nature, curcumin is poorly soluble in the neutral solvent. Curcumin's solubility is improved slightly in basic conditions but then degrades. Absence of heat results in a very less dissolving rate for the curcumin molecule. When slight heat was introduced, it increases kinetic energy, which allows the DESs more efficiently to break the curcumin, which is held together by stronger intermolecular attraction.

The curcumin solubility in TM hydrophobic-based NADESs without and with slight heat was shown in figure 6 . The curcumin solubility in different hydrophobic-based NADESs (TM, TC, and CM) with slight heat was shown in figure 7. 


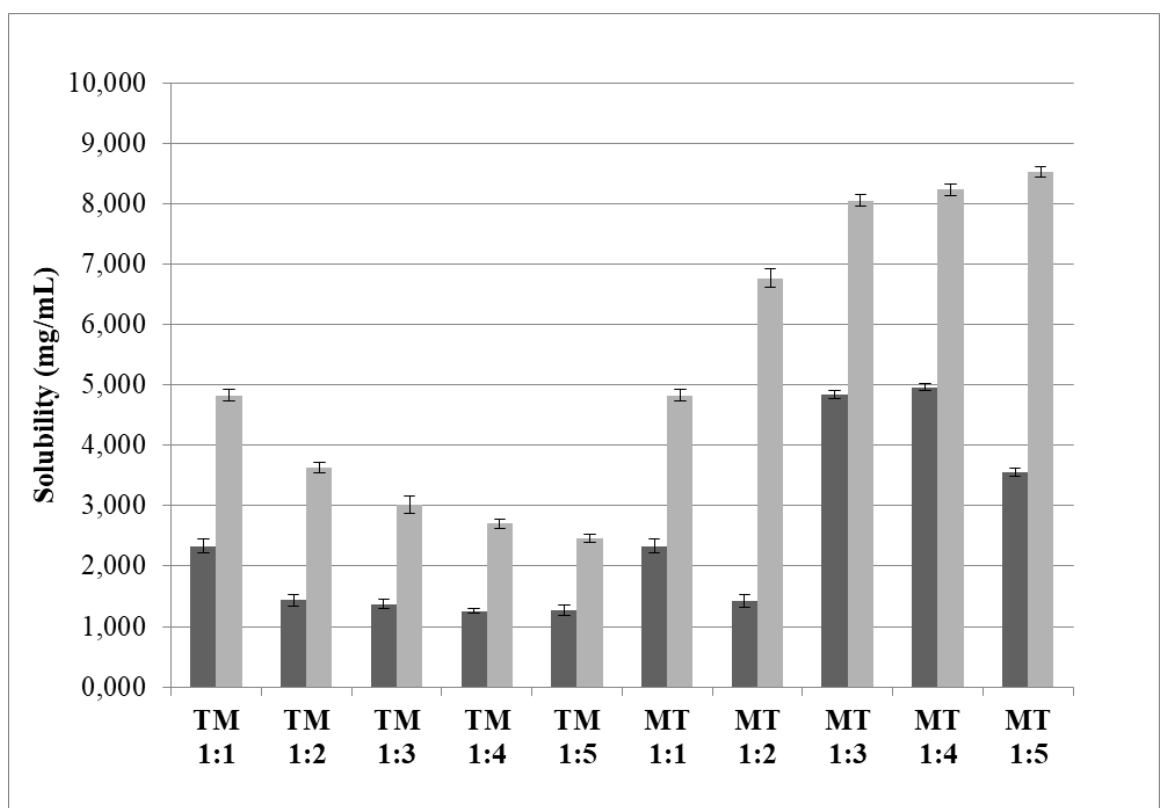

Figure 6. Curcumin solubility in TM based hydrophobic NADES without and with slight heat.

( $\square)$ without heat $(\square)$ with heat

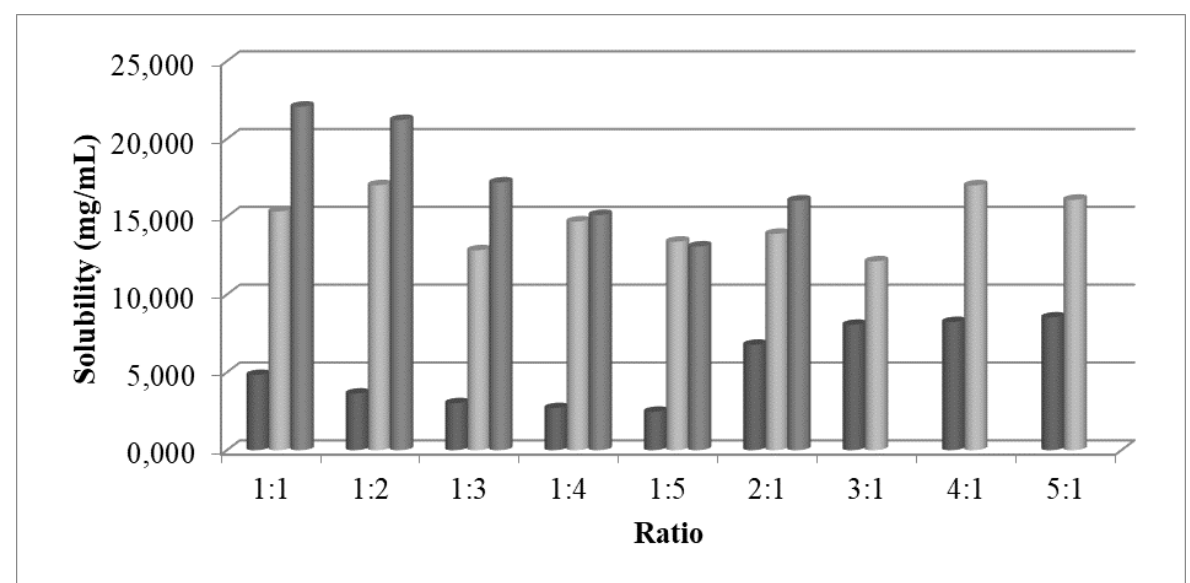

Figure 7. Curcumin solubility in different hydrophobic-based NADES with slight heat.

( $\square)$-TM ( $\square$ ')-TC ( $\square)$-CM

The solubility of curcumin in TM-DES was found to be nearly double when it was dissolved in $1 \mathrm{~h}$ at $35-40^{\circ} \mathrm{C}$ at $500 \mathrm{rpm}$ when compared to $48 \mathrm{~h}$ stirring at $500 \mathrm{rpm}$ in RT. Curcumin solubility was decreased when the concentration of menthol was increased, and thymol concentration was kept constant. Meanwhile, curcumin solubility was increased when the thymol concentration was increased, and menthol concentration was kept constant.

It was observed that more amount of curcumin was dissolved in a slightly warmed eutectic solvent, even at a less stirring time of $60 \mathrm{~min}$ when compared to the eutectic solvent at RT stirred for $48 \mathrm{~h}$.

In TC-DESs (1:1 to 1:5), when the thymol concentration was kept constant and the camphor concentration increased, the temperature was between $35-40^{\circ} \mathrm{C}$ for $1 \mathrm{~h}$. the solubility of curcumin was found to be $12.93 \mathrm{mg} / \mathrm{ml}$ to $17.12 \mathrm{mg} / \mathrm{ml}$. In CT-DESs (1:1 to 1:5), the camphor concentration was kept constant. The thymol concentration was increased, and the temperature was between $35-40^{\circ} \mathrm{C}$ for $1 \mathrm{~h}$. the solubility of curcumin was found to be 12.55 $\mathrm{mg} / \mathrm{ml}$ to $17.01 \mathrm{mg} / \mathrm{ml}$.

In CM-DESs (1:1 to 1:5), when the camphor concentration was kept constant and the menthol concentration increased, the temperature was between $35-40^{\circ} \mathrm{C}$ for $1 \mathrm{~h}$. the solubility of curcumin was found to be $22.073 \pm 0.095 \mathrm{mg} / \mathrm{ml}$ to $13.087 \pm 0.230 \mathrm{mg} / \mathrm{ml}$. As the 
concentration of menthol was increased, the solubility of curcumin was decreased. In CMDESs (1:1 and 1:2) as the camphor concentration was kept constant and the menthol concentration increased, the temperature was between $35-40^{\circ} \mathrm{C}$ for $1 \mathrm{~h}$. the solubility of curcumin was found to be $22.073 \pm 0.095 \mathrm{mg} / \mathrm{ml}$ to $16.040 \pm 0.305 \mathrm{mg} / \mathrm{ml}$. The solubility of curcumin in CM-DESs (1:3 to 1:4) was not determined due to the gel and solid like the preparation's consistency.

The solubility of curcumin is often a limiting factor for its bioavailability, with consequences in its therapeutic effectiveness. The earlier studies showed that eutectic solvents are able to increase drug solubility. Curcumin shows very low aqueous solubility in water, but in CM-DES (1:1), curcumin's solubility was more.

Considering the structure of curcumin, curcumin can exist in keto and enol forms depends upon the condition. The keto group's presence and the alcoholic group in curcumin favor better interactions with the CM-based DESs even though it contains two phenolic groups.

\section{Conclusions}

Curcumin, the main bioactive constituent of turmeric, has been shown to have an extensive range of pharmacological actions. Due to its poor aqueous solubility, stability, and bioavailability, curcumin health benefits are limited. Efforts are currently made by different research groups in curcumin-based formulations deals with to improve their solubility, stability, and bioavailability. In this study, the formation of clear NADES was obtained with slight heat. There was no difference in $\mathrm{pH}$ for the NADESs prepared without and with heat. Regarding the viscosity CM-DES (1:1) showed less viscosity when compared to other NADESs. The solubility of curcumin in different NADESs was determined at RT and at a slight increase in temperature. From this present study, it was concluded that curcumin's solubility was found to be nearly double when it was dissolved in NADES for $1 \mathrm{hr}$ at $35-40^{\circ} \mathrm{C}$ at $500 \mathrm{rpm}$ compared to $48 \mathrm{hrs}$ stirring at $500 \mathrm{rpm}$ in RT. Among different NADESs, DES prepared with $\mathrm{CM}(1: 1)$ ratio showed more curcumin solubility when compared to other NADESs.

\section{Funding}

This research received no external funding.

\section{Acknowledgments}

The access to scientific literature and lab facility to perform the stability studies are provided jointly by Vinayaka Mission's College of Pharmacy, Salem, and Sankaralingam Bhuvaneswari College of Pharmacy, Sivakasi. One of the authors (Mr. T. Raja Sekharan) thanks Dr. Balamurugan Jeganathan, $1^{\text {st }}$ Director, Formulation Development at Simcere Pharmaceutical Group, Nanjing, Jiangsu, China, for his constant support while writing this research article. The authors wish to acknowledge Dr. Balamurugan Jeganathan for the valuable academic help.

\section{Conflicts of Interest}

The authors declare no conflict of interest. 


\section{References}

1. Prasad, S.; Aggarwal, B.B. Chapter-13 Turmeric, the Golden Spice: From Traditional Medicine to Modern Medicine. In: Herbal Medicine: Biomolecular and Clinical Aspects. Benzie IFF., Wachtel-Galor, S. 2nd Eds. CRC Press/Taylor \& Francis: Boca Raton (FL), 2011.

2. Khanna, K.; Kohli, S.K.; Kaur, R.; Bhardwaj, A.; Bhardwaj, V.; Ohri, P.; Sharma, A.; Ahmad, A.; Bhardwaj, R.; Ahmad, P. Herbal immune-boosters: Substantial warriors of pandemic Covid-19 battle. Phytomedicine : International Journal Of Phytotherapy and Phytopharmacology 2020, https://doi.org/10.1016/j.phymed.2020.153361.

3. Zielińska, A.; Alves, H.; Marques, V.; Durazzo, A.; Lucarini, M.; Alves, T.F.; Morsink, M.; Willemen, N.; Eder, P.; Chaud, M.V.; Severino, P.; Santini, A.; Souto, E.B. Properties, extraction methods, and delivery systems for curcumin as a natural source of beneficial health effects. Medicina 2020, 56, https://doi.org/10.3390/medicina56070336.

4. Salehi, B.; Stojanović-Radić, Z.; Matejić, J.; Sharifi-Rad, M.; Anil Kumar, N.V.; Martins, N.; Sharifi-Rad, J. The therapeutic potential of curcumin: A review of clinical trials. European Journal of Medicinal Chemistry 2019, 163, 527-545, https://doi.org/10.1016/j.ejmech.2018.12.016.

5. Gupta, H.; Gupta, M.; Bhargava, S. Potential use of turmeric in COVID-19. Clinical and Experimental Dermatology 2020, 45, 902-903, https://doi.org/10.1111/ced.14357.

6. Tarun, V. Role of curcumin as an antioxidant. J Primary Care Dentistry and Oral Health 2020, 1, 8-11, https://doi.org/10.4103/jpcdoh.jpcdoh_1_20.

7. Manoharan, Y.; Haridas, V.; Vasanthakumar, K.C.; Muthu, S.; Thavoorullah, F.F.; Shetty, P. Curcumin: a wonder drug as a preventive measure for COVID19 management. Indian Journal of Clinical Biochemistry 2020, 35, 373-375, https://doi.org/10.1007/s12291-020-00902-9.

8. Geethanjali, A.; Lalitha, P.; Jannathul, F.M. Analysis of curcumin content of turmeric samples from various states of India. Int J Pharma Chem Res 2016, 2, 55-62.

9. Nguyen, T.T.H.; Si, J.; Kang, C.; Chung, B.; Chung, D.; Kim, D. Facile preparation of water soluble curcuminoids extracted from turmeric (Curcuma longa L.) powder by using steviol glucosides. Food Chemistry 2017, 214, 366-373, https://doi.org/10.1016/j.foodchem.2016.07.102.

10. Firmansyah, A.; Nugrahani, I.; Wirasutisna, K.R.; Ibrahim, S. Formation of boron - silica based mesoporous and studies of its adsorption ability for curcuminoids. Biointerface Research in Applied Chemistry 2020, 10, 4977-4981, https://doi.org/10.33263/BRIAC0102.977981.

11. Gao, Y.; Chen, G.; Luan, X.; Zou, M.; Piao, H.; Cheng, G. Improved oral absorption of poorly soluble curcumin via the concomitant use of borneol. AAPS PharmSciTech 2019, 20, https://doi.org/10.1208/s12249-019-1364-5.

12. Sathisaran, I.; Devidas Bhatia, D.; Vishvanath Dalvi, S. New curcumin-trimesic acid cocrystal and antiinvasion activity of curcumin multicomponent solids against 3D tumor models. International Journal of Pharmaceutics 2020, 587, https://doi.org/10.1016/j.ijpharm.2020.119667.

13. Jagannathan, R.; Abraham, P.M.; Poddar, P. Temperature-dependent spectroscopic evidences of curcumin in aqueous medium: A mechanistic study of its solubility and stability. The Journal of Physical Chemistry B 2012, 116, 14533-14540, https://dx.doi.org/10.1021/jp3050516.

14. Sharifi-Rad, J.; Rayess, Y.E.; Rizk, A.A.; Sadaka, C.; Zgheib, R.; Zam, W.; Sestito, S.; Rapposelli, S.; NeffeSkocińska, K.; Zielińska, D.; Salehi, B.; Setzer, W.N.; Dosoky, N.S.; Taheri, Y.; El Beyrouthy, M.; Martorell, M.; Ostrander, E.A.; Suleria, H.A.R.; Cho, W.C.; Maroyi, A.; Martins, N. Turmeric and its major compound curcumin on health: bioactive effects and safety profiles for food, pharmaceutical, biotechnological and medicinal applications. Frontiers in Pharmacology 2020, 11,. https://doi.org/10.3389/fphar.2020.01021.

15. Carvalho Henriques, M.; Faustino, M.A.F.; Santos Braga, S. Curcumin innovative delivery forms: Paving the 'Yellow Brick Road' of antitumoral phytotherapy. Applied Sciences 2020, 10, https://doi.org/10.3390/app10248990.

16. Morais, E.S.; Lopes, A.M.d.C.; Freire, M.G.; Freire, C.S.R.; Coutinho, J.A.P.; Silvestre, A.J.D. Use of ionic liquids and deep eutectic solvents in polysaccharides dissolution and extraction processes towards sustainable biomass valorization. Molecules 2020, 25, https://doi.org/10.3390/molecules25163652.

17. Emami, S.; Shayanfar, A. Deep eutectic solvents for pharmaceutical formulation and drug delivery applications. Pharmaceutical Development and Technology 2020, 25, 779-796, https://doi.org/10.1080/10837450.2020.1735414.

18. Ünlü, A.E.; Arıkaya, A.; Takaç, S. Use of deep eutectic solvents as catalyst: A mini-review. Green Processing and Synthesis 2019, 8, 355-372, https://doi.org/10.1515/gps-2019-0003.

19. Cao, J.; Cao, J.; Wang, H.; Chen, L.; Cao, F.; Su, E. Solubility improvement of phytochemicals using (natural) deep eutectic solvents and their bioactivity evaluation. Journal of Molecular Liquids 2020, 318, https://doi.org/10.1016/j.molliq.2020.113997.

20. Tamilvanan, S.; Gill, S.; Kaur, I.; Rahman, S.N.R.; Pawde, D.M.; Katari, O.; Hmingthansanga, V.; Sekharan, T.R. Candidiasis management: current status of allopathic drugs and utility of coriander-based oil-less 
emulsions. Letters in Applied NanoBioScience 2019, 8, 586-590, https://doi.org/10.33263/LIANBS83.586590.

21. Wikene, K.O.; Bruzell, E.; Tønnesen, H.H. Characterization and antimicrobial phototoxicity of curcumin dissolved in natural deep eutectic solvents. European Journal of Pharmaceutical Sciences 2015, 80, 26-32, https://doi.org/10.1016/j.ejps.2015.09.013.

22. Rachmaniah, O.; Jumiati, F.L.; Hesti, S.N.; Rachimoellah, M. Tailoring properties of acidic types of natural deep eutectics solvents (NADES): Enhanced solubility of curcuminoids from Curcuma zeodaria. Paper presented at MATEC Web of Conferences 2018, 156, https://doi.org/10.1051/matecconf/201815601011.

23. Jeliński, T.; Przybyłek, M.; Cysewski, P. Natural deep eutectic solvents as agents for improving solubility, stability and delivery of curcumin. Pharmaceutical Research 2019, 36, https://doi.org/10.1007/s11095-0192643-2.

24. Almeida, C.M.R.; Magalhães, J.M.C.S.; Souza, H.K.S.; Gonçalves, M.P. The role of choline chloride-based deep eutectic solvent and curcumin on chitosan films properties. Food Hydrocolloids 2018, 81, 456-466, https://doi.org/10.1016/j.foodhyd.2018.03.025.

25. Phaechamud, T.; Tuntarawongsa, S.; Charoensuksai, P. Evaporation behavior and characterization of eutectic solvent and ibuprofen eutectic solution. AAPS PharmSciTech 2016, 17, 1213-1220, https://doi.org/10.1208/s12249-015-0459-X.

26. Determining and $\quad$ Calculating $\quad$ 2020. Available at https://chem.libretexts.org/Bookshelves/Physical_and_Theoretical_Chemistry_Textbook_Maps/Suppleme ntal_Modules_(Physical_and_Theoretical_Chemistry)/Acids_and_Bases/Acids_and_Bases_in_Aqueous_S olutions/The_pH_Scale/Determining_and_Calculating_pH\#: :text=The\%20pH\%20of\%20an\%20aqueous,i on\%20concentration\%20in\%20the\%20solution.

27. Chettupalli, A.K.; Ananthula, M.; Amarachinta, P.R.; Bakshi, V.; Yata, V.K. Design, Formulation, in-vitro and ex-vivo evaluation of atazanavir loaded cubosomal gel. Biointerface Research in Applied Chemistry 2021, 11, 12037-12054, https://doi.org/10.33263/BRIAC114.1203712054.

28. Duarte, A.R.C.; Ferreira, A.S.D.; Barreiros, S.; Cabrita, E.; Reis, R.L.; Paiva, A. A comparison between pure active pharmaceutical ingredients and therapeutic deep eutectic solvents: Solubility and permeability studies. European Journal of Pharmaceutics and Biopharmaceutics 2017, 114, 296-304, https://doi.org/10.1016/j.ejpb.2017.02.003.

29. Van Osch, D.J.G.P.; Dietz, C.H.J.T.; Van Spronsen, J.; Kroon, M.C.; Gallucci, F.; Van Sint Annaland, M.; Tuinier, R. A search for natural hydrophobic deep eutectic solvents based on natural components. ACS Sustainable Chemistry \& Engineering 2019, 7, 2933-2942, https://doi.org/10.1021/acssuschemeng.8b03520.

30. Dwamena, A.K. Recent advances in hydrophobic deep eutectic solvents for extraction. Separations 2019, 6, https://doi.org/10.3390/separations6010009.

31. Skulcova, A.; Russ, A.; Jablonsky, M.; Sima, J. The pH behavior of seventeen deep eutectic solvents. BioRes 2018, 13, 5042-5051. 